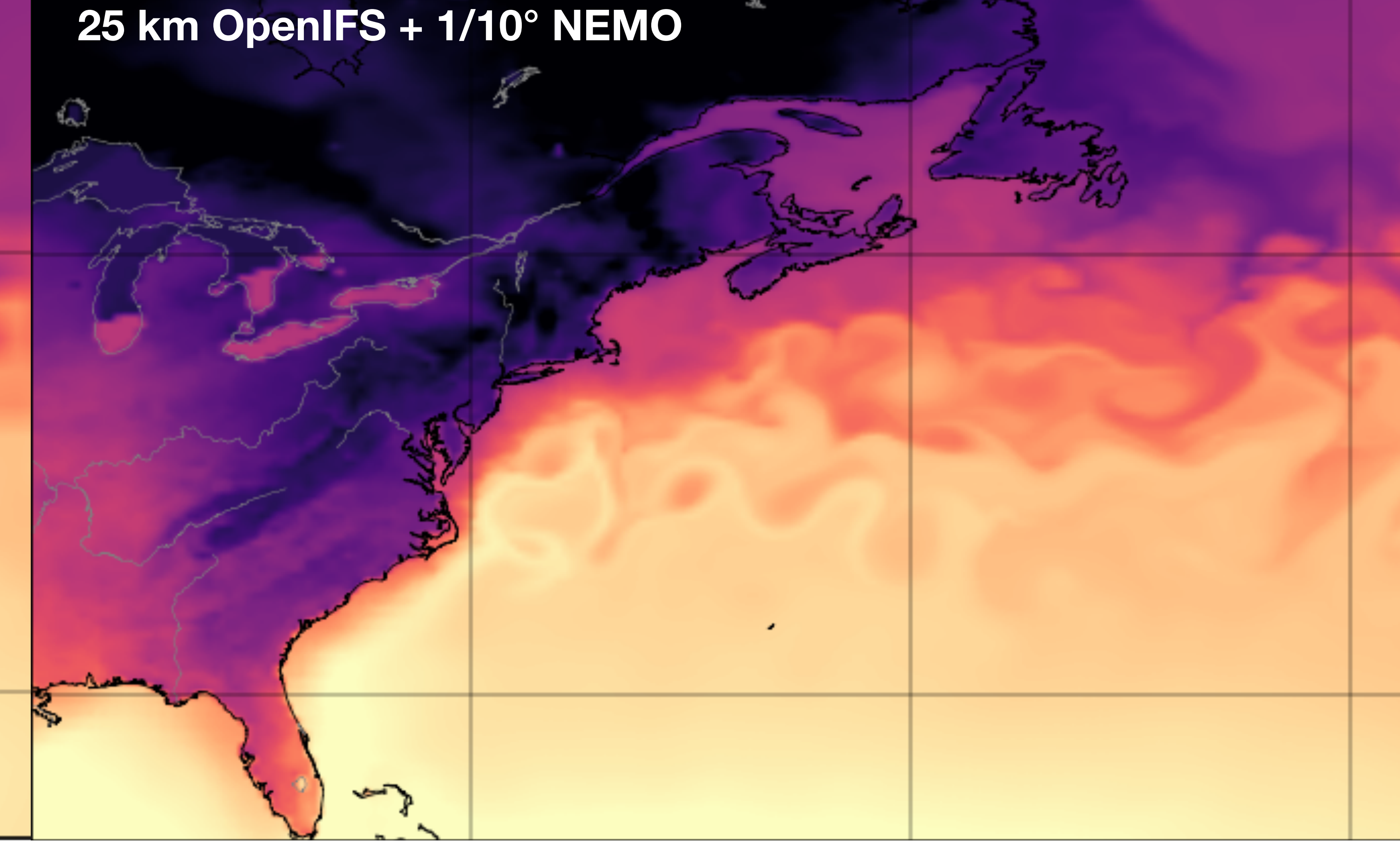

\title{
Greatness from small beginnings
}

Impact of oceanic mesoscale on weather extremes and large-scale atmospheric circulation in midlatitudes

\section{Joakim Kjellsson, GEOMAR/CAU}

Eric Maisonnave, CERFACS

Wonsun Park, GEOMAR

Torge Martin, GEOMAR

Mojib Latif, GEOMAR

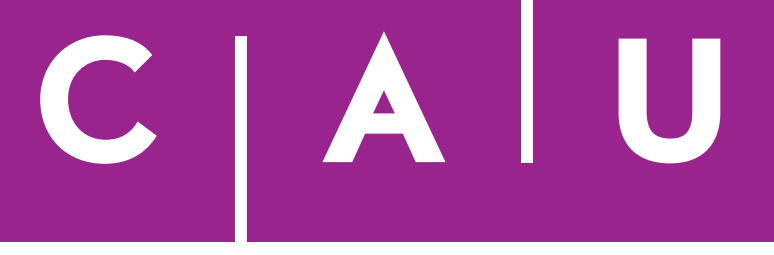

MOIb Latis G OMAR


- ROADMAP (JPI Oceans) project to investigate role of ocean on atmospheric circulation and extremes.

- What is the specific role of the oceanic mesoscale? Requires mesoscale-resolving models!

- Global models with $\mathrm{dx} \sim 10 \mathrm{~km}$ insanely expensive. Unstructured/nested grids a way forward.

- But fluxes are calculated on atmosphere grid => loss of detail in coupling with low-res atmosphere.
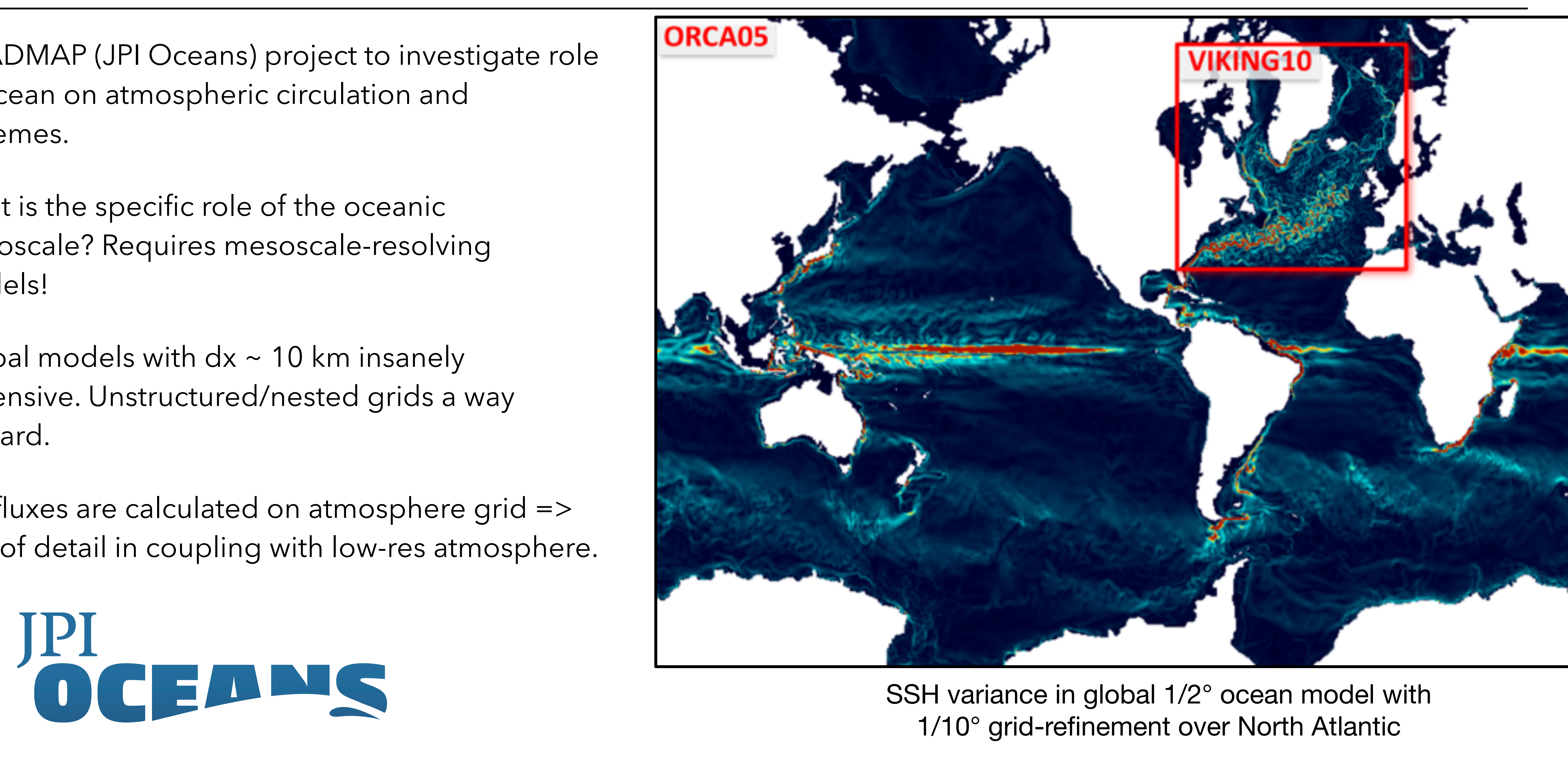


\section{Grid-refinement technique}

- AGRIF = Adaptive Grid Refinement In Fortran (Debreu et al. 2008)

- Auto-generates code for a sub-model which communicates with the base model on the lateral boundaries.

- Refine grid by 4-5 times in AGRIF. Global $1 / 2^{\circ}+$ N.Atl $1 / 10^{\circ}$ or Global $1 / 4^{\circ}+$ N.Atl $1 / 20^{\circ}$

Reduce time step, mom. viscosity, tracer diffusion.

- Use cases in NEMO and ROMS

- Nest within nest possible, but not multiple nests in different regions.

Only horizontal grid refinement. Vertical refinement in development.

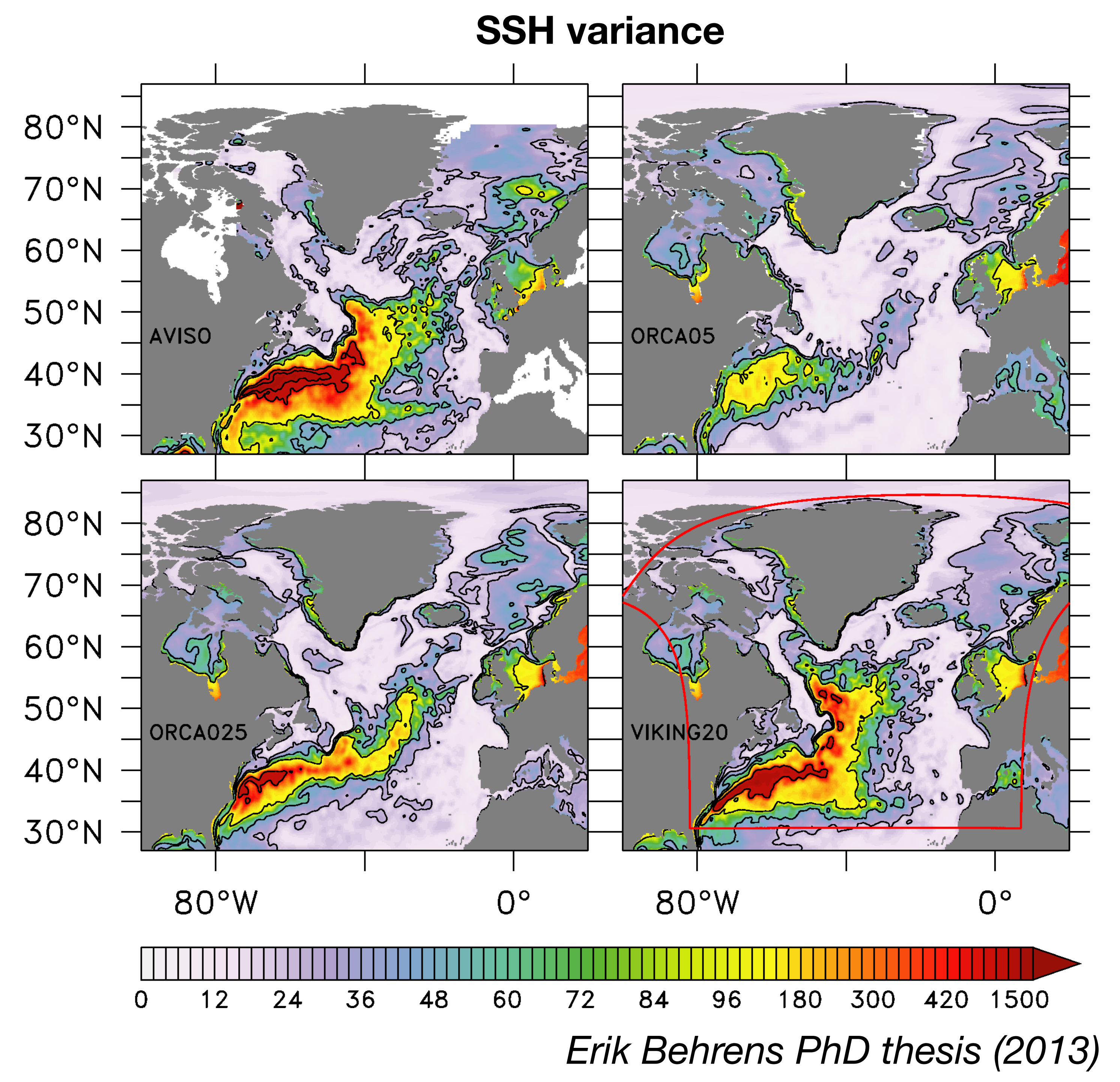


- OpenIFS 40r1. Either $125 \mathrm{~km}$ or $25 \mathrm{~km}$ horizontal resolution. Both 91 levels. Not feasible to run ECHAM6 at these resolutions...

- NEMO v3.6 + LIM2. 1/2 + 1/10 North Atlantic grid. 46 levels.

- 3-hourly coupling (ongoing work to compare $1 \mathrm{hr} v$ s $3 \mathrm{hr}$ coupling).

- ESM-Tools as runtime environment to modify namelist files, link input files, post process output, etc.

OpenIFS, ECHAM, ICON, FESOM2, NEMO, MPIOM standalone + any combination as a coupled model via OASIS.

See display by Dirk Barbi et al. (ESSI 2.11, Thu 16:15-18:00, D802) 


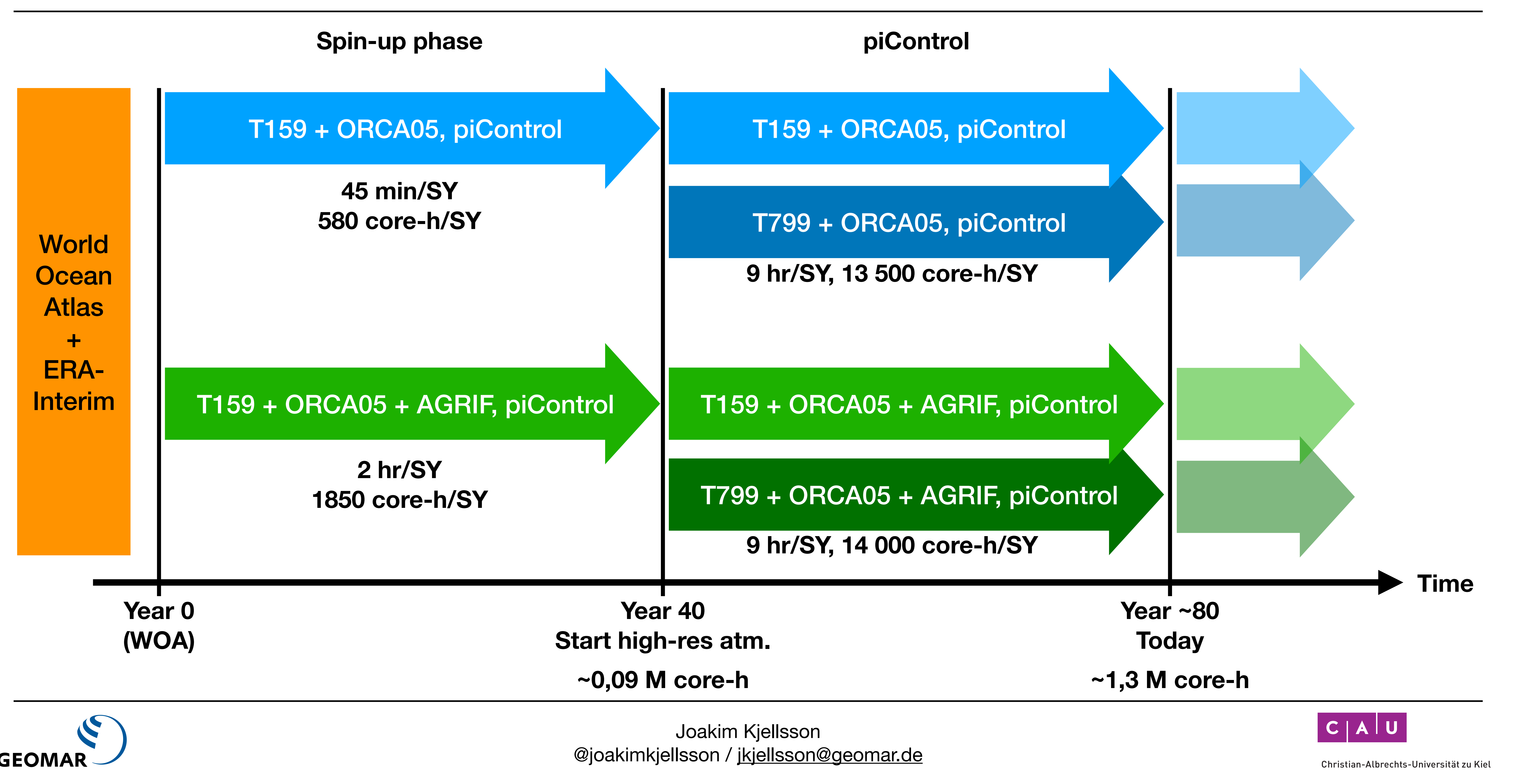




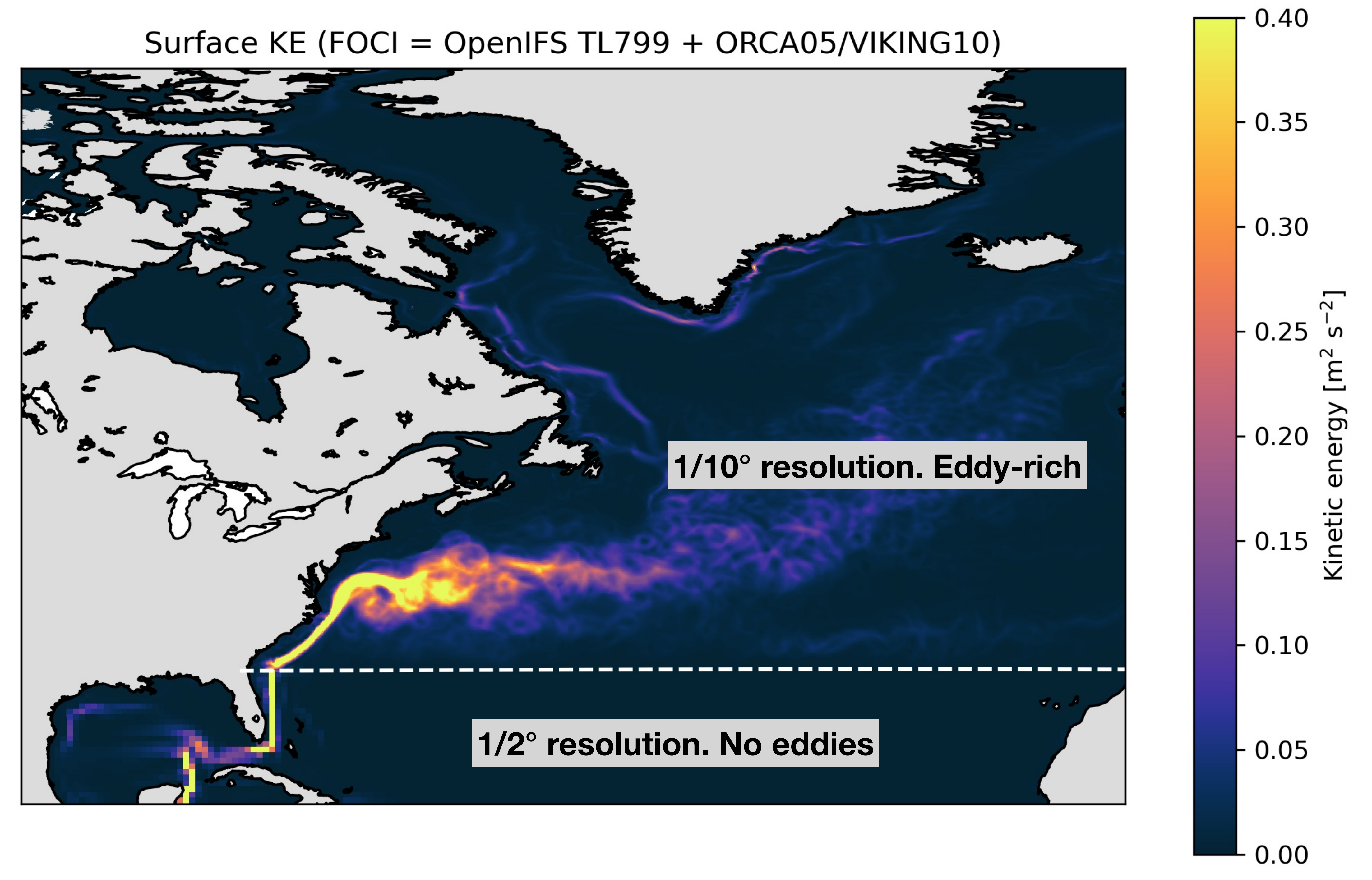




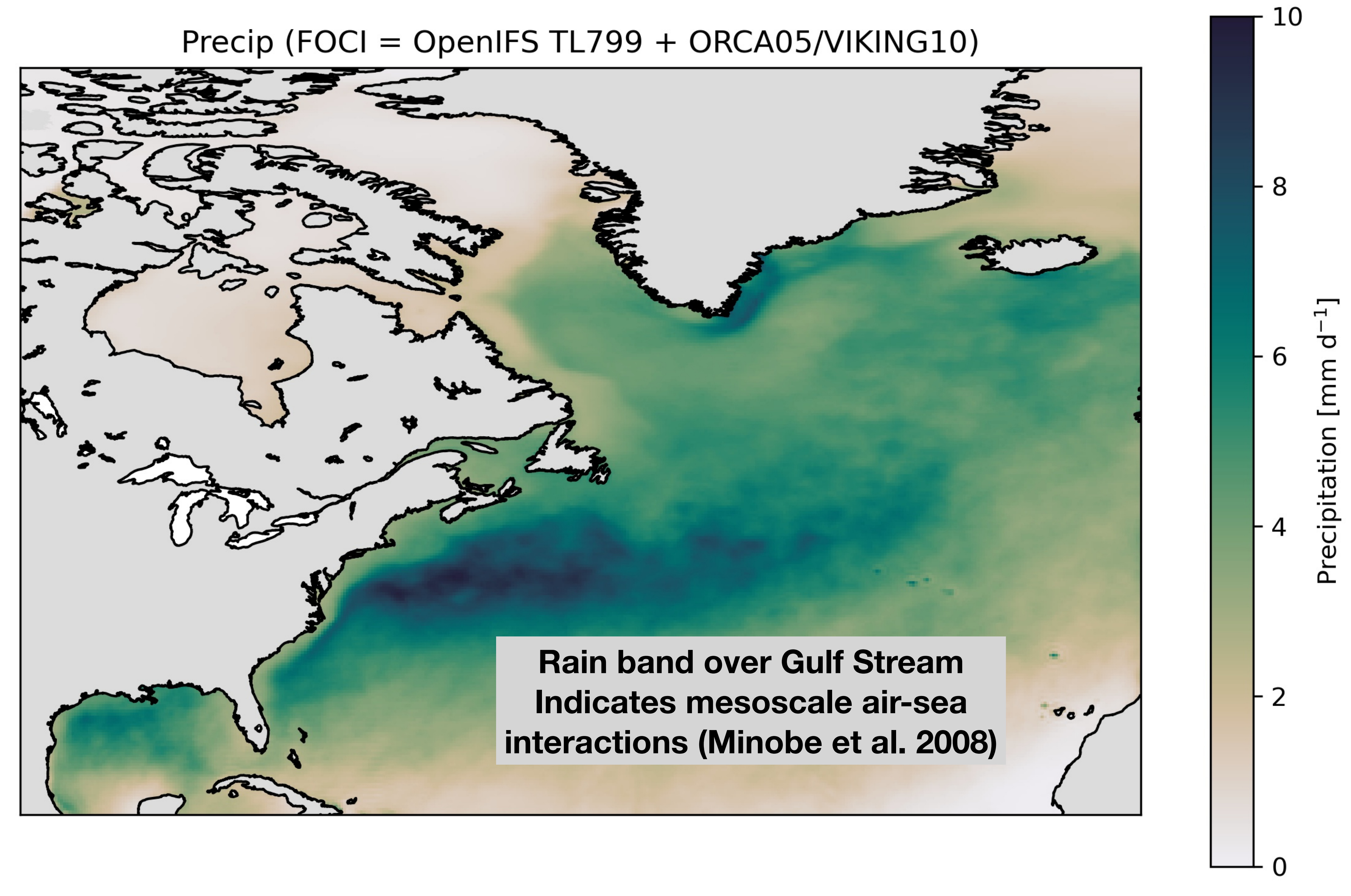


- Most climate models have a cold bias in North Atlantic due to poorly resolved North Atlantic Current.

- Using $1 / 10^{\circ}$ nest in North Atlantic gives much better ocean dynamics and reduces cold bias.

I.e. a local warming over North Atlantic is expected.

- Warming also propagates in over the Eurasian continent.

- Also strong warming of Labrador Sea and cooling of Nordic Seas.

Changes in ocean circulation and/or sea-ice distribution?
DJF mean 2m temperature Difference between run with ocean nest and without nest

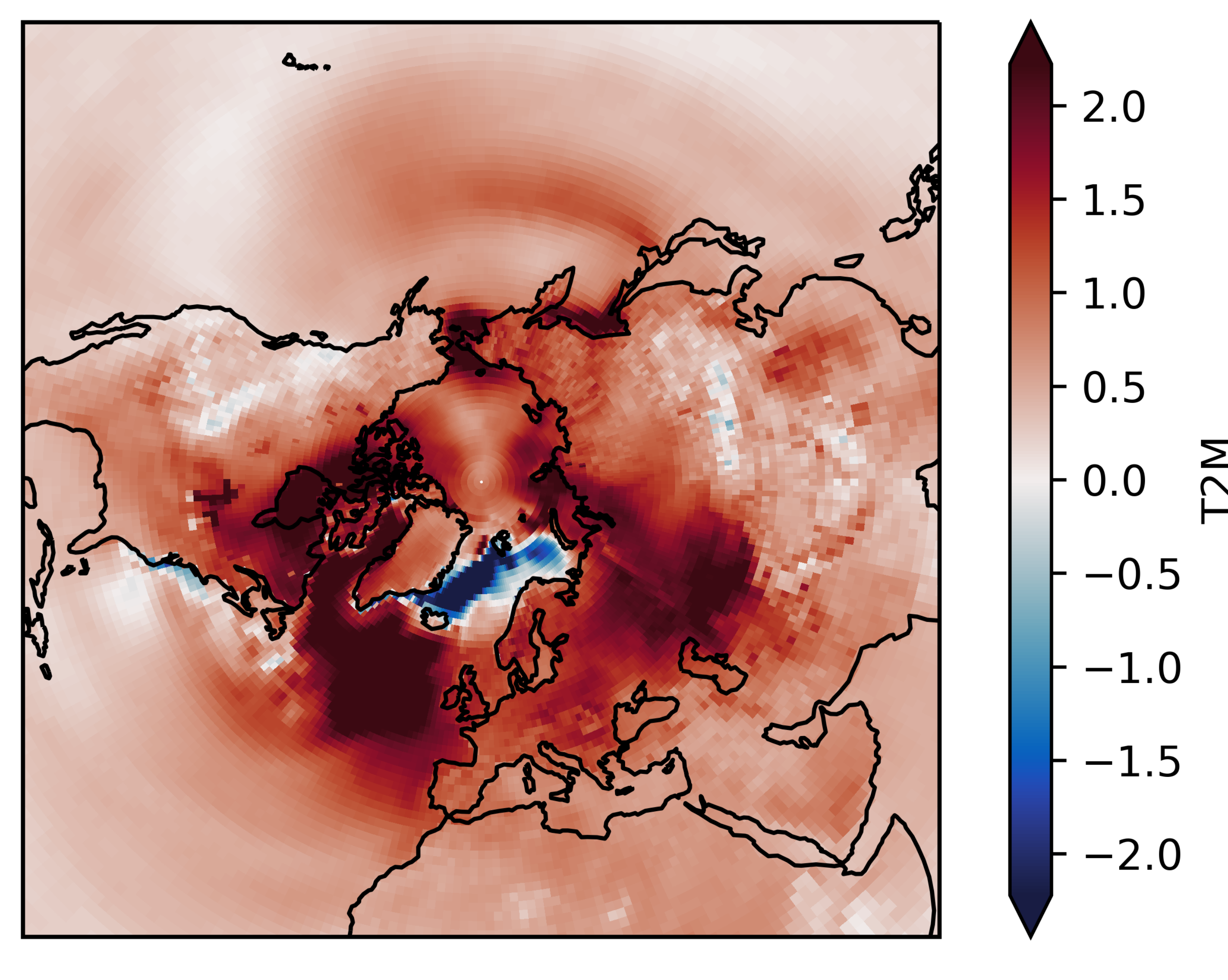


- In the run with eddy-rich ocean nest the westerlies (here $10 \mathrm{~m}$ zonal wind) shifts northward over the North Atlantic.

- Can explain how warming over North Atlantic spreads in over the continent due to simple advection.

DJF mean $10 \mathrm{~m}$ zonal wind

Difference between run with ocean nest and without nest

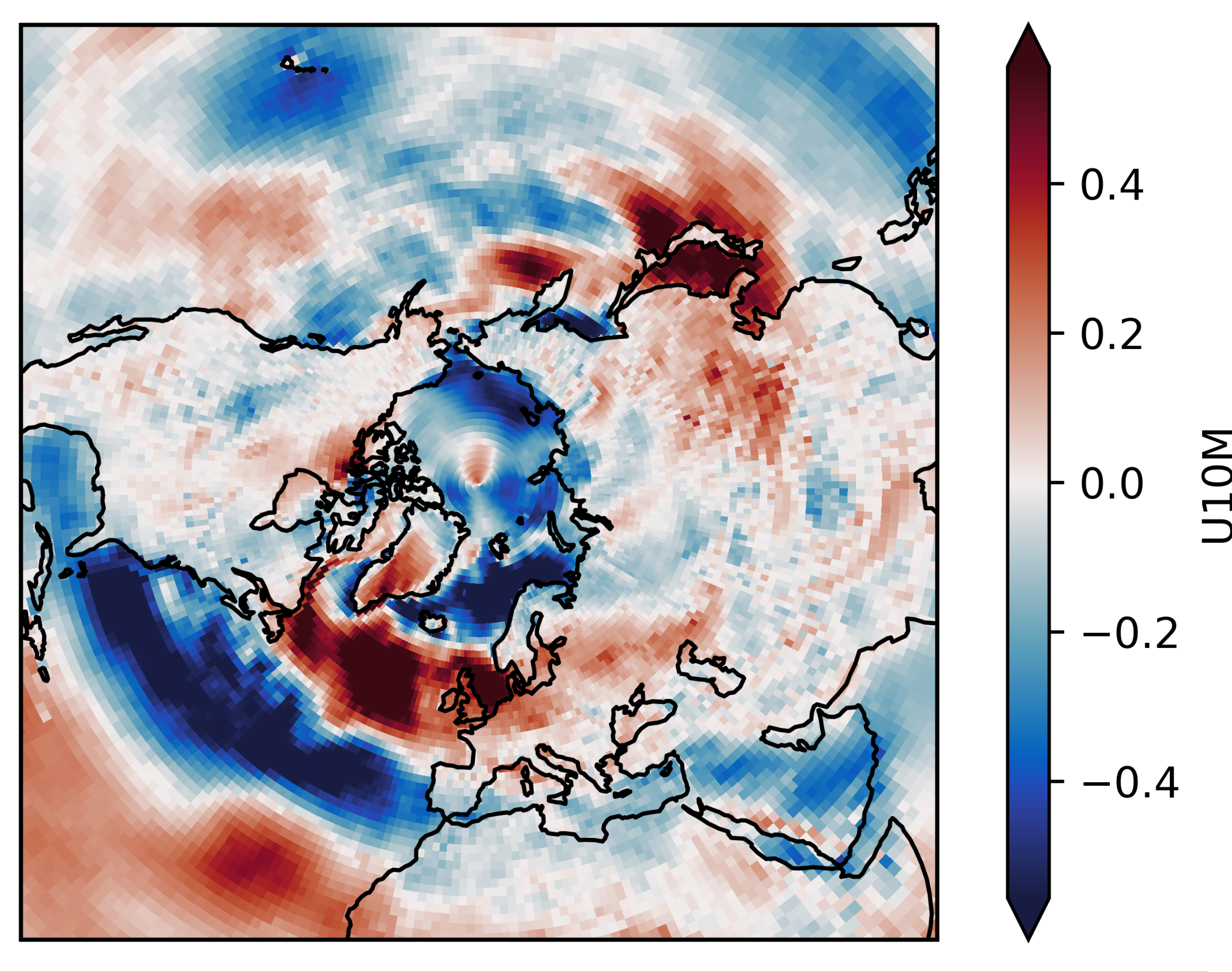


Variance in daily MSLP (DJF) [hPa^2]

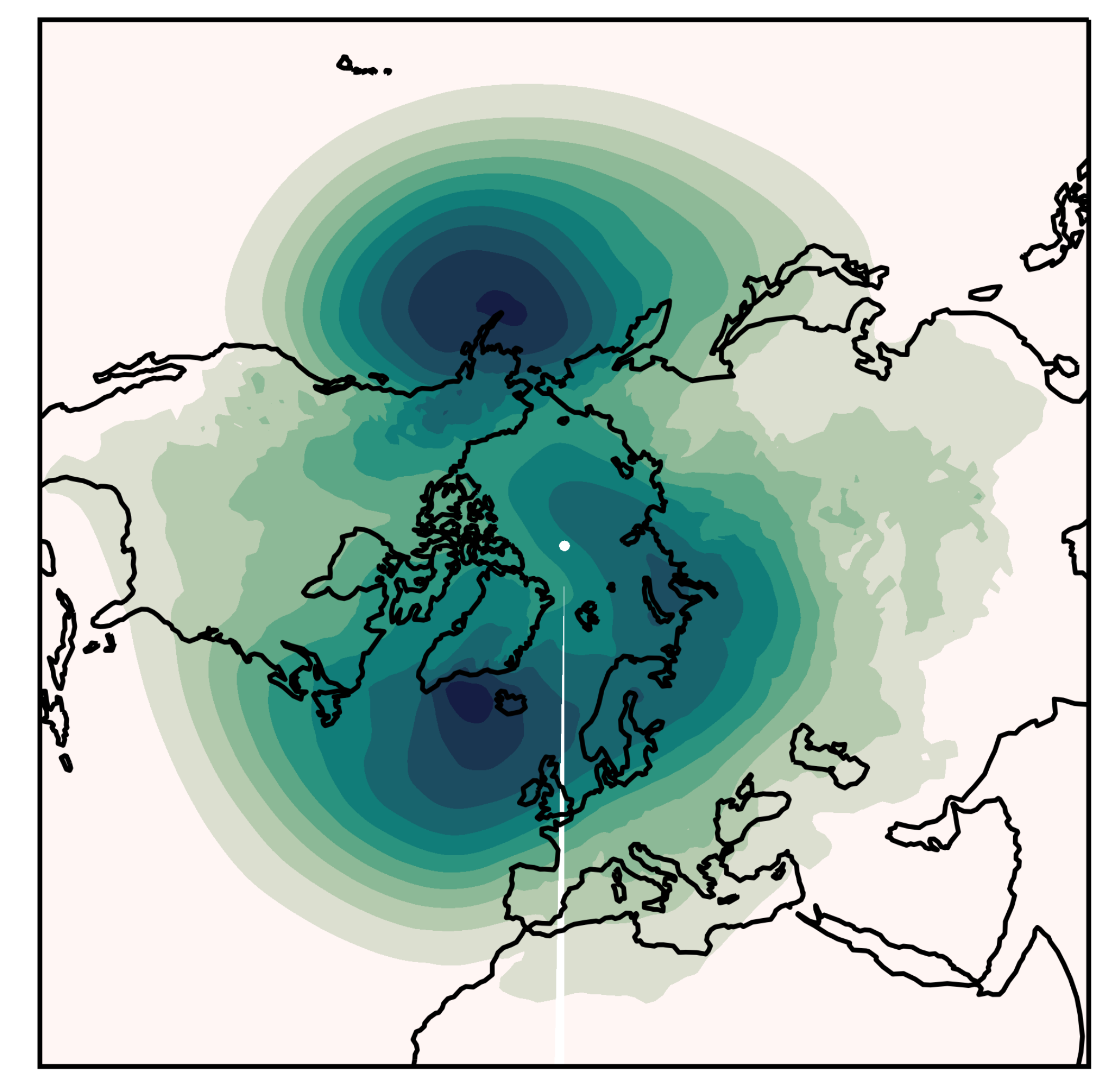

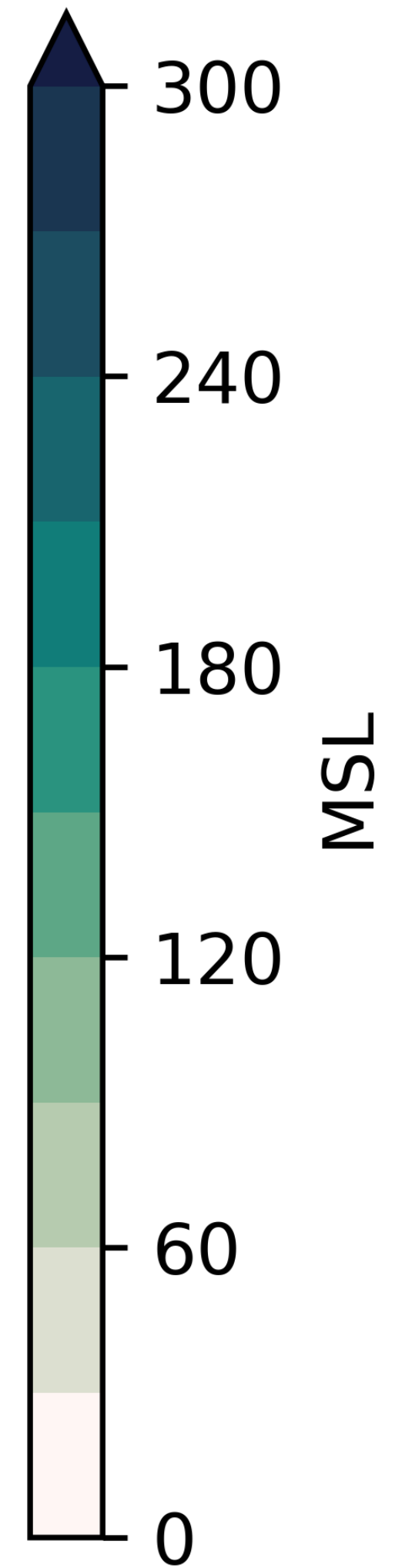

Difference in variance with and without nest

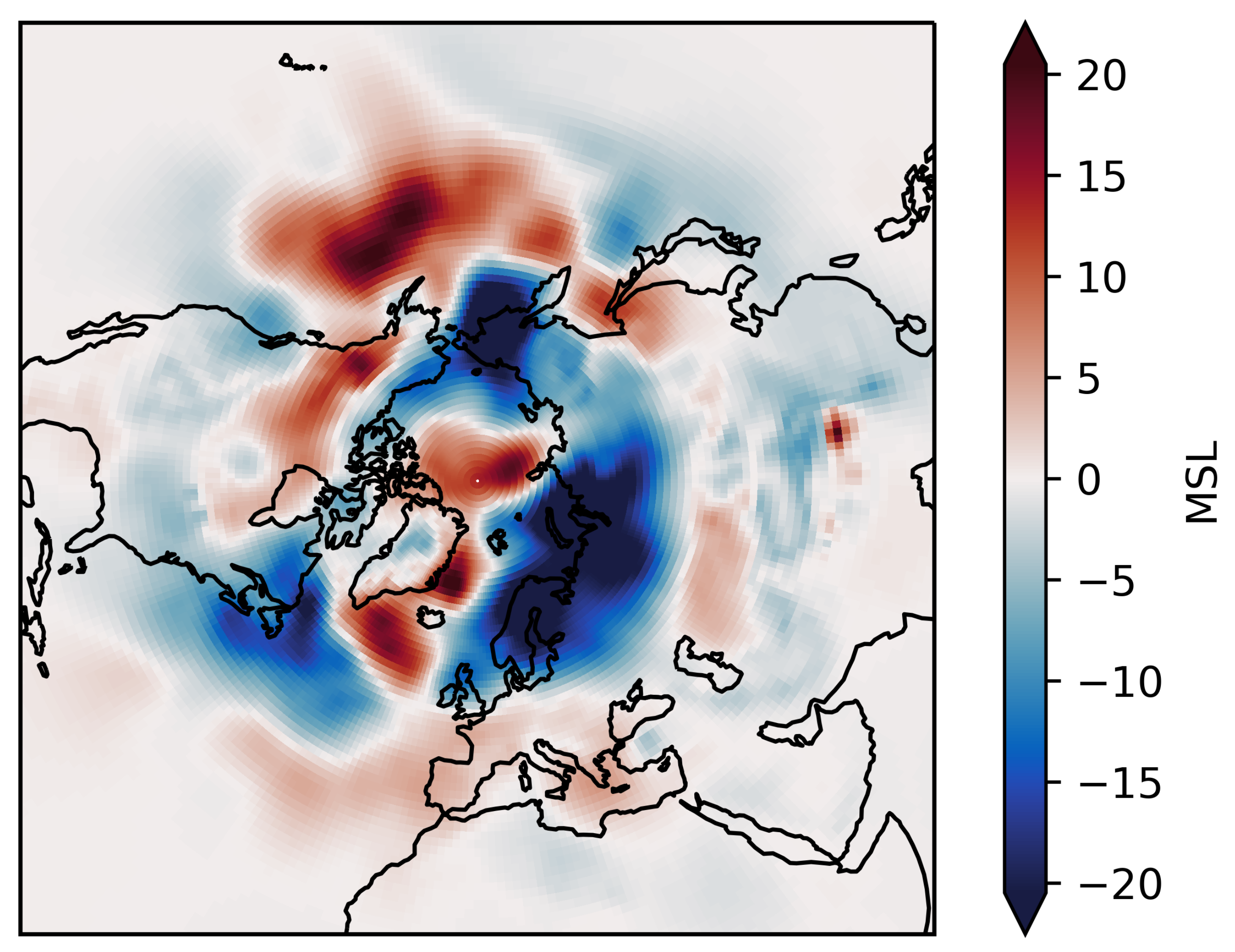

Increased variance near peak MSLP variance over N. Atlantic and N. Pacific. Less variance over Northern Europe and Barents Sea.

Warming due to ocean nest weakening storms over Northern Europe? 
- Eddy-rich ocean nest $\left(1 / 10^{\circ}\right)$ gives better ocean dynamics than $1 / 2^{\circ}$ ocean model. Reduces N. Atl. cold bias => warming of lower troposphere.

- Model with ocean nest shows warming over most of the midlatitudes.

- How does the ocean nest impact midlatitude cyclones? Weaker storms over Northern Europe? Use cyclone-tracking code?

- The simulations are part of a testing phase of coupled model with ocean nests. Multi-ensemble HighResMIP-like simulations planned for the coming years. More robust results with more data?

- Do you want to work on this?

3-year postdoc position at GEOMAR available! Get in touch!

This work has benefited from a trans-national service of the IS-ENES3 project funded by the European Union's Horizon 2020 research and innovation programme under grant agreement No 824084 
Bonus slide 1: The "zoo" of climate models with ECMWF IFS

\begin{tabular}{|c|c|c|c|c|c|c|}
\hline & ECMWF-IFS & EC-Earth3 & CNRM-ESM2 & $\begin{array}{c}\text { FOCI2 } \\
\text { (OpenIFS) }\end{array}$ & AWI-CM3.1 & EC-Earth4 \\
\hline IFS & IFS cy 43 r3 & $\begin{array}{l}\text { IFS cy36r4 } \\
\text { (atm. only) }\end{array}$ & ARPEGE-Climat v6 & OpenIFS cy43r3 & OpenIFS cy43r3 & OpenIFS cy43r3 \\
\hline NEMO & NEMO v3.4 & NEMO v3.6 & NEMO v3.6 & NEMO v3.6 & FESOM2 & NEMO v4 \\
\hline Coupler & Single-executable & OASIS3-MCT3 & OASIS3-MCT3 & OASIS3-MCT4 & OASIS3-MCT4 & OASIS3-MCT4 \\
\hline $\begin{array}{l}\text { Grid } \\
\text { refinement }\end{array}$ & No & No & No & AGRIF & Unstr. grid & No \\
\hline Hor. res. & $\begin{array}{c}\text { Tco199/ORCA1 } \\
\text { T }_{\text {co399/ORCA025 }}\end{array}$ & $\begin{array}{c}T_{L} 255 / O R C A 1 \\
T_{L} 511 / O R C A 025\end{array}$ & $\mathrm{~T}_{\mathrm{L}} 127$ / ORCA1 & $\begin{array}{c}\mathrm{T}_{\mathrm{L}} \text { 159L91/ORCA05 } \\
\mathrm{T}_{\mathrm{L}} \text { 799L91/ORCA05 } \\
+ \text { VIKING10 }\end{array}$ & $\begin{array}{c}\text { Tco159/CORE2 } \\
\text { Tco319/BOLD }\end{array}$ & $\begin{array}{c}\text { Tco159/ORCA1 } \\
T_{\text {co319/ORCA025 }}\end{array}$ \\
\hline ESM & No & ESM & ESM & $\mathrm{AOGCM}$ & AOGCM & $\mathrm{ESM}^{*}$ \\
\hline MIPs & HighResMIP & all MIPs & all MIPs & No MIPs & No MIPs & CMIP7 \\
\hline
\end{tabular}




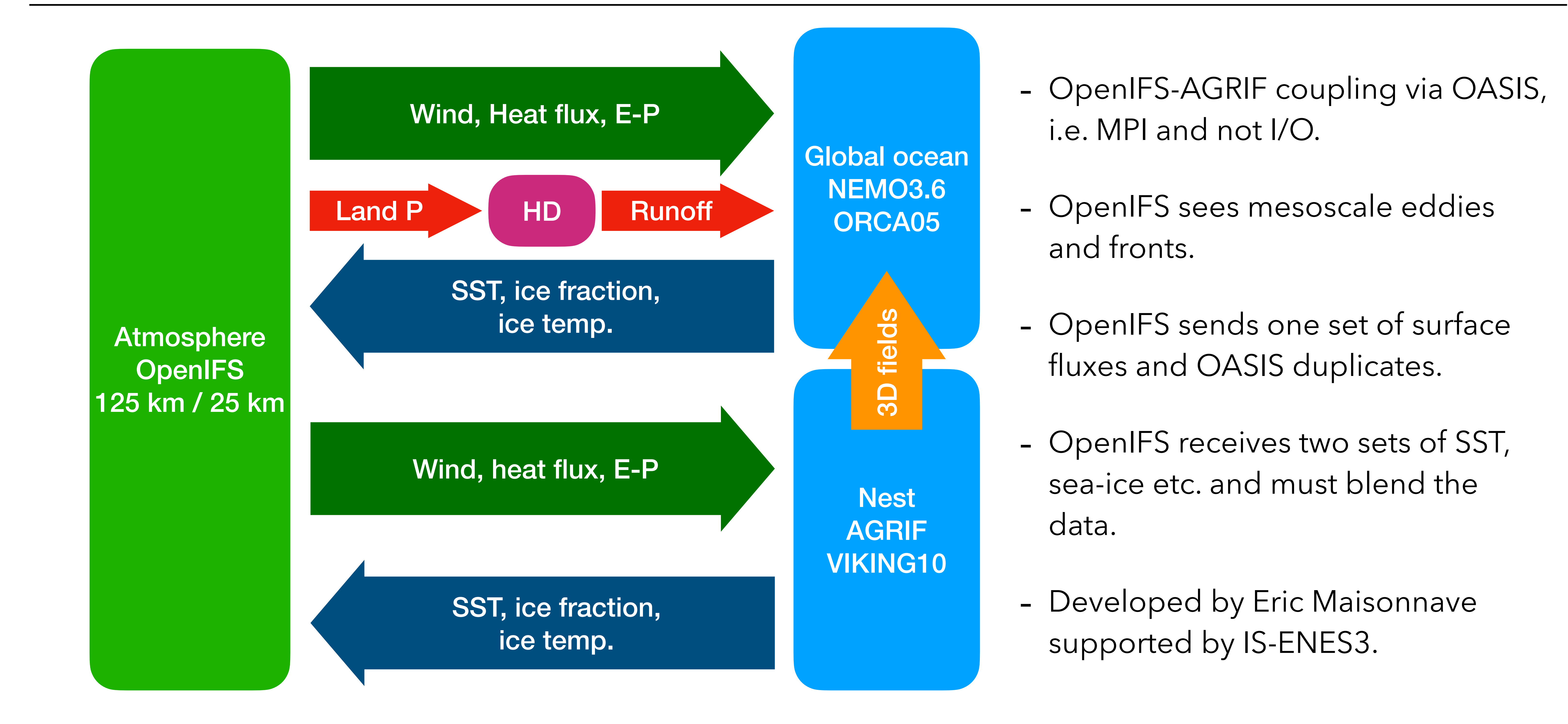


Local AGRIF sponge on NEMO global grid

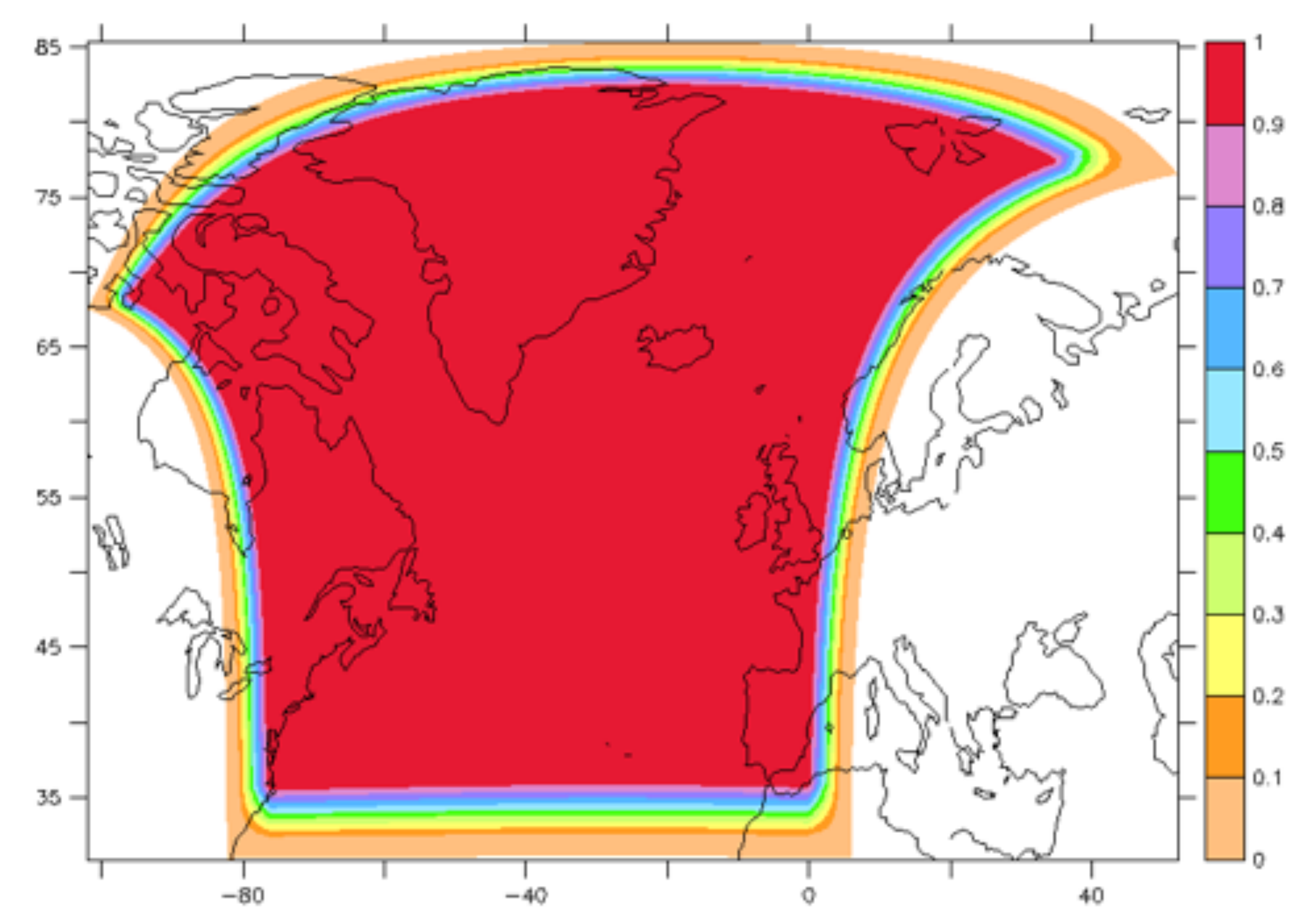

Local AGRIF sponge on OpenIFS global grid

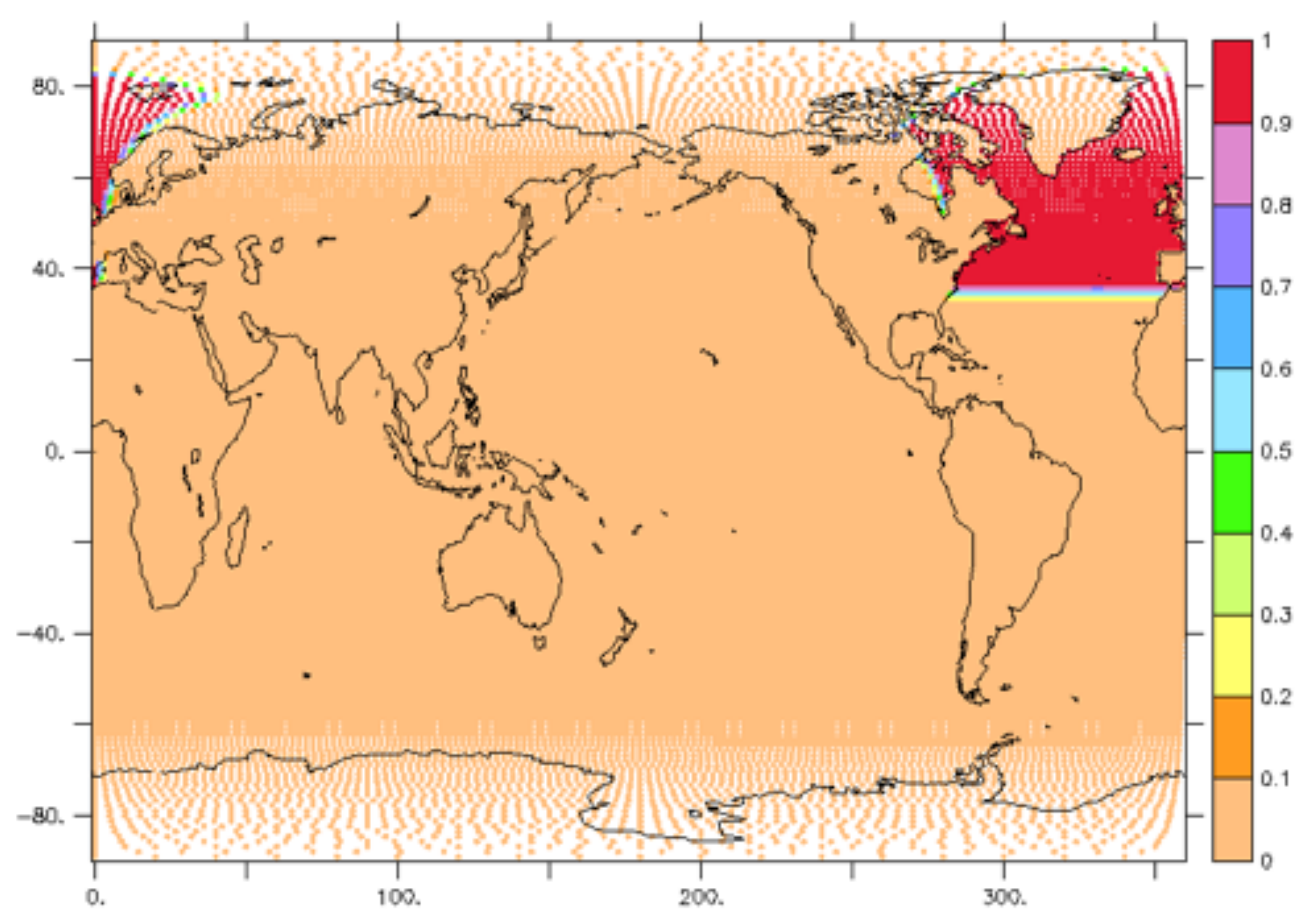

- All coupling fields from AGRIF are multiplied by sponge in OpenIFS. Interpolated by OASIS. 
- A long ( 1500 yr) spin-up is need $\epsilon$ to study the full coupled system.

- But I'm inpatient, so I only do 40year spin-up and only focus on upper ocean and atmosphere.

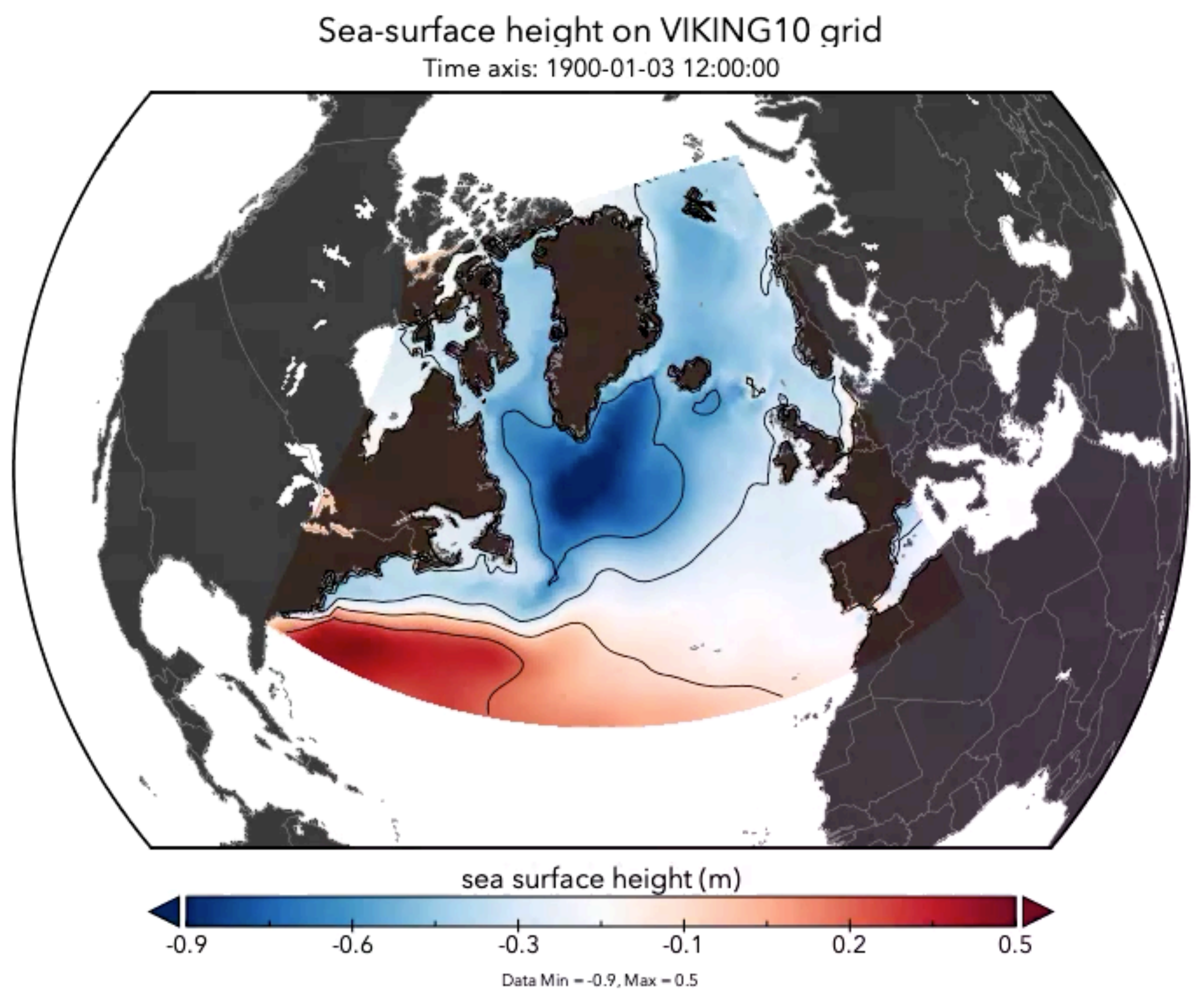

